\title{
Hypophosphataemia in anorexia nervosa
}

\author{
L Håglin
}

The prevalence, causes, and consequences of hypophosphataemia in the clinical treatment of various diseases are described in the literature, but are not so seriously regarded as a severe electrolytical disturbance. ${ }^{1-3}$ The clinical conditions when hypophosphataemia should be suspected are listed in fig 1 . There is a triad of disturbances: hypokalaemia, hypomagnesaemia, and hypophosphataemia which often follows trauma, and glucose overload. ${ }^{4}$ In anorexia nervosa patients, hypokalaemia, hypochloraemia, and metabolic alkalosis are commonly seen. ${ }^{5-7}$

A high prevalence of hypophosphataemia is seen among post-traumatic and/or critically ill patients undergoing intensive care. ${ }^{8}$ Infectious diseases are also associated with the risk of developing hypophosphataemia. ${ }^{9}$ Immunological disturbances can result from a deficiency of several nutrients, such as zinc. ${ }^{10}$ Hypophosphataemia was found in anorexia nervosa patients with respiratory distress and signs of pneumonia. ${ }^{11-13}$ Recently, it was reported that the main causes of death of patients with anorexia nervosa was electrolytic disturbance and infection. ${ }^{11}{ }^{14}$

The incidence of hypophosphataemia in a hospital population is usually associated with undernutrition followed by refeeding. ${ }^{15-18} \mathrm{Re}-$ cent reports of hospital undernutrition should alert health and medical staff to the significance of low serum phosphate concentrations. For example, overambitious treatment of undernourished patients with high energy intake

1999

Accepted 22 August 2000 can cause hypophosphataemia related paralysis and respiratory insufficiency. ${ }^{19}$

Hypophosphataemia with symptoms of phosphate depletion was first described in connection with starvation during wartime and in prisoners when refeeding was initiated after a period of phosphate loss. ${ }^{20}{ }^{21}$ Milk (rich in phosphate) was a life saver. ${ }^{21} 22$ Protein energy undernutrition predisposes to hypophosphataemia. ${ }^{43}$ When a gradual breakdown of tissue takes place during starvation, total depletion of the body's phosphate stores may develop, even though the serum phosphate level most often remains normal. ${ }^{1}$ Anorexia in adolescent girls occurs at a serum phosphate level of $0.8-1.0$ $\mathrm{mmol} / \mathrm{l} \cdot{ }^{24}$ Reference values vary with age.

It has been stated that anorexia nervosa is a condition characterised by protein energy undernutrition, which may also explain other deficiencies said to exist in anorexia nervosa patients. ${ }^{25}$ Most deficiencies have a protein source, for example zinc, selenium, potassium, phosphate and calcium, in addition to vitamin D deficiency, due to low fat intake. ${ }^{26}$ These deficiencies may also contribute to loss of appetite.

Anorexia, well described symptom in phosphate depletion and/or hypophosphataemia, has frequently been documented before other disturbances in both experimental and clinical conditions. ${ }^{4}$ Eight out of 10 case reports on the sequelae of hypophosphataemia in anorexia nervosa have described female patients. In one study, only two of 65 adolescents with anorexia nervosa were boys. ${ }^{7}$ Causes and consequences are both related to gender, the consequences of phosphate depletion differing because of the smaller muscle mass of women than of men. ${ }^{27}$ Progressive hypercalciuria and negative calcium balance developed in women but not men. ${ }^{27} \mathrm{~A}$ smaller total phosphate pool in female rats has been found in experiments. ${ }^{28}$ Fatigue and muscle weakness, often reported in anorexia nervosa patients, may be an early hypophosphataemic sign of phosphate depletion, as is loss of appetite. ${ }^{6724}$

The dangerous consequences of phosphate depletion emphasise the urgency of this discussion (box 1). The fatal condition is connected with disturbed oxidative phosphorylation and adenosine triphosphate (ATP) depletion in almost all vital functions. Loss of appetite can predispose to major complications, such as growth disturbances, neurological sequelae, and demineralisation of the skeleton. Hypophosphataemia has been reported in anorexia nervosa patients in connection with neurological complications and both respiratory and congestive heart failure. Several case reports of hypophosphataemia in anorexia nervosa, in addition to the most

Figure 1 Clinical conditions when hypophosphataemia should be suspected (PEM = protein energy malnutrition). 


\author{
Box 1: Consequences of phosphate \\ depletion and/or hypophosphataemia \\ for different functions in anorexia \\ nervosa \\ - Loss of appetite (anorexia). \\ - Neuromuscular. \\ - Cardiopulmonary. \\ - Haematological. \\ - Gastrointestinal. \\ - Renal. \\ - Endocrinological. \\ - Skeletal. \\ And \\ Life threatening due to ATP depletion and \\ deranged composition of phospholipids in \\ membranes of the nervous system, heart, \\ red corpuscles. \\ And \\ Sudden death.
}

frequently cited reports from experimental studies, are referred to in the present paper.

The purpose of this review is to expand our knowledge of the role of phosphate, especially its depletion, a neglected condition in the clinical situation.

\section{Underlying pathophysiologyl \\ biochemistry}

Reduced protein synthesis has been described in experimental studies as being associated with restricted eating. ${ }^{29}$ It was concluded that an increased amount of phosphate is needed for ATP production which in turn is a prerequisite for protein synthesis (maintenance of the nitrogen balance) and appetite. This shows that phosphate depletion leads to anorexia by contributing to low protein synthesis.

Normal serum phosphate concentrations do not preclude pre-existing total body depletion of phosphate, with a low intracellular pool vis$\grave{a}$-vis nitrogen (lower phosphate/nitrogen ratio). ${ }^{30}$ Starvation with weight loss results in a negative nitrogen balance affecting the skeleton, muscles and hormones, with changes in the protein nutritional status (low albumin concentrations). Low serum albumin is a late and severe manifestation of protein energy undernutrition, if there is a superimposed infection.

When anabolism is induced by high energy intake - and particularly carbohydrates - as the main source of energy, phosphate shifts from serum into cells, thus giving rise to hypophosphataemia. ${ }^{15}$ The priority of fat metabolism during starvation and semistarvation is superseded in the refeeding situation by carbohydrate priority and an increased need of phosphate for phosphorylation and protein synthesis. ${ }^{31}$ Intracellular trapping of phosphate is described when metabolism switches from lipolysis to glycolysis. ${ }^{30}$ This concerns blockage of the intracellular utilisation of phosphate without any necessary change in the phosphate/nitrogen ratio. As phosphate is involved in almost all cellular processes, the specific disturbances in different conditions are even more difficult to identify.

Low levels of ATP in red blood cells cause hypoxia and haemolysis while contractility is reduced in the myocardium and respiratory muscles. ${ }^{42}$ Experimentally induced phosphate depletion affects left ventricular energy generation, impairing myocardial contractile force. ${ }^{32}{ }^{33}$ Red blood cells are dependent on a certain level of extracellular phosphate, as the means of membrane transport is passive diffusion. Low levels of both ATP and 2,3 diphosphoglycerate have been reported in hypophosphataemia in a patient with anorexia nervosa. ${ }^{34}$ Low levels of ATP in leukocytes impaired immunofunction. ${ }^{4}$ An intracellular depletion of inorganic phosphate, which has been shown in experimental studies to be correlated to serum levels (concentrations are about 100:1), first affects the phosphorylation of creatine to creatinine phosphate, which is the primary donor of phosphate to adenosine diphosphate. ${ }^{1}{ }^{32}$ Secondly, resynthesis of ATP is diminished. Electrolytic imbalance across cellular membranes, caused by a diminished adenosine triphosphatase activity, results in an intracellular accumulation of calcium, sodium, chloride, and water. This is probably the mechanism of oedema described in patients with anorexia nervosa and also in protein energy undernutrition. ${ }^{23} 35$

Disturbances of the acid-base balance and electrolyte status have been reported in cases of anorexia nervosa and in phosphate depletion. ${ }^{511303637}$ Lactic acidosis and rhabdomyolysis can be caused by deranged phosphate metabolism. ${ }^{30}$ A comparable condition has been described in an anorexia nervosa patient who had metabolic alkalosis and respiratory acidosis. ${ }^{6}$ Starvation, with severe nutrient deficiencies, may accelerate phosphate loss via the urine. ${ }^{24}{ }^{38}$ Such loss is associated with increased acid excretion. ${ }^{37}$

The ketone bodies produced by starvation, and/or the lactic acids produced by physical training, lead to an excess of hydrogen ions. The phosphate buffer, whose main source is bone, eliminates these ions. Bone, a dynamic store for calcium and phosphate, helps to regulate the composition of the extracellular fluid. An early sign of phosphate depletion in women is calcium loss via the urine, and increased risk of hypercalcaemia. ${ }^{27}$ Significantly higher serum concentrations of calcium and lower serum phosphate were observed in patients with anorexia nervosa than in controls. ${ }^{39}$ The hypercalcaemia is per se connected with morbidity and mortality risk.

Animals fed a low phosphate diet developed anorexia and increased bone resorption. ${ }^{40} 41 \mathrm{~A}$ catabolic condition, such as starvation, mobilises phosphate from both skeletal muscle and bone. Resorption of the skeleton due to an acidic state may explain the low bone mineral content and is the result of acidosis (fig 2). ${ }^{42}$ Bone resorption supplies alkali to blood and urine. $^{30}$ 
Decomposition of the skeleton. The effect of altered $\mathrm{pH}$ in extracellular fluids, in addition to the effects of phosphate depletion on the $\mathrm{pH}$, need to be observed

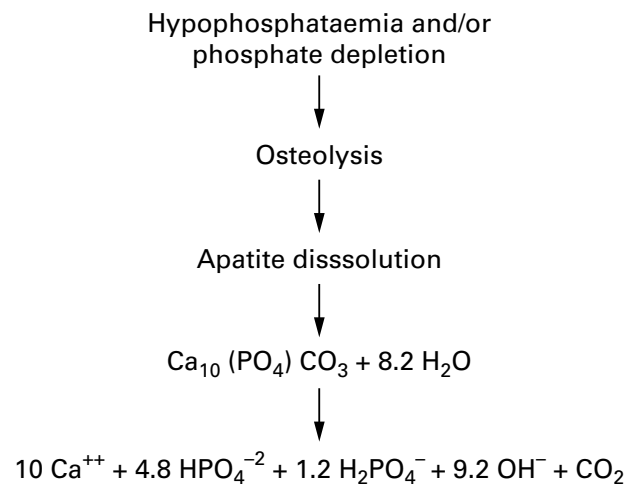

Figure 2 Decomposition of the skeleton.

It has been found that the resorption of phosphate in the kidney is reduced in metabolic acidosis. ${ }^{38}$ High urinary phosphate excretion due to an extremely low threshold for phosphate resorption has also been described in a patient with anorexia nervosa. ${ }^{34}$ By oral or intravenous phosphate supplementation, both phosphate and acid excretion via the urine can be made to increase. This acidotic correction produced by readjusting phosphate depletion results in weight gain.

Experimental studies in animals indicate that accelerated growth, despite an acceptable intake of phosphate, produces the symptoms of phosphate depletion. ${ }^{43}$ Phosphate depletion before or during puberty can affect the metabolism of chondrocytes in the growth plate-thus inhibiting growth of the long bones. Short stature was described in one patient with anorexia nervosa, who contracted the disease at the age of 11 years. ${ }^{45}$ She had slightly raised serum phosphate values, probably the result of release from bone in connection with femoral head collapse.

Rickets may be caused by deficiency of calcium, vitamin D, and phosphate.$^{46}$ Repletion with phosphate, with increased collagen turnover, heals rickets. ${ }^{47}$ It seems that an increased need of phosphate, in the catch-up growth, for example in premature infants, explains the development of the pathophysiology of rickets. ${ }^{48}$ Premature closure of the epiphyseal growth plate is observed in stress induced disturbances, possibly resulting in disruption of the proliferation of chondrocytes in the epiphyseal cartilage. Since the metabolism of these cells is highly glycolytic (anaerobic), their growth depends on substrates penetrating the cells and the production of glycolytic ATP, which can hinder the proliferation and differentiation of the chondrocytes. Could it be that the reduced protein synthesis and growth retardation are an adaptation to the low energy intake? Phosphate depletion could be the signal for this state, as neither energy metabolism nor anabolism is maintained without the presence of phosphate. If phosphate depletion causes loss of appetite in order to maintain a balance between energy produced and metabolism, the undernutrition per se needs to be analysed. Reduced DNA synthesis in growth plate cartilage has been attributed in experimental studies to undernutrition. ${ }^{46}$

\section{Clinical consequences}

In patients with anorexia nervosa, starvation, vomiting, laxative abuse, and exercise all contribute to a negative phosphate balance. Loss of phosphate via stool and urine, in addition to low intake during periods of accelerated growth (puberty), can cause symptoms of phosphate depletion. The occurrence of hypophosphataemia in anorexia nervosa, concomitant with nutritional recovery, may reveal a phosphate deficiency. Avoidance of phosphate containing (protein rich) foods (milk, fish, meat, egg) when combined with low energy intake (protein energy undernutrition), depletes the body's pool of phosphate, leading to subnormal serum phosphate concentrations. Measurement of serum phosphate concentration yields little information regarding total phosphate body pool.

Protein energy undernutrition in a 12 year old girl and a 9 year old boy predisposed to refeeding hypophosphataemia. ${ }^{18}$ It is known that the level of serum phosphate is correlated to age and growth and that resorption of phosphate in the kidneys is higher in growing youngsters than in adults, and has also been described experimentally. ${ }^{43}{ }^{49}$ This demonstrates the increased need of phosphate during growth.

It is obvious also from clinical studies that the level of phosphate intake is closely related to body growth and that the risk of phosphate depletion increases during periods when the growth rate is high. ${ }^{43}$ Physical growth and the mineralisation of the long bones during puberty are associated with high serum phosphate levels.

In adults, hypophosphataemia causes osteomalacia, and rickets in children. Phosphate depletion and hypophosphataemic rickets in children stunts growth. In experimental studies, phosphate depletion restricted weight gain and caused growth disturbances. ${ }^{50} 51$

Patients with anorexia nervosa have been found to have osteoporosis, with significantly reduced trabecular bone volume on biopsy. ${ }^{52-54}$ Undernutrition at the time of attaining peak bone mass could account for the low bone mass of anorexia nervosa patients. ${ }^{55}$ Does the bone mass loss accompany weight loss? It is known that weight for height is correlated with bone mineral density in patients with anorexia nervosa as well as in controls. ${ }^{56}$ Weight loss is correlated with debility due to phosphate depletion, while weight gain is dangerous unless enough phosphate is given in relation to energy requirements. ${ }^{57}$ Restoration of body weight also improved bone mass before the oestrogen level was readjusted, indicating the importance of an overall delivery of nutrients to cause optimal accretion of tissue. ${ }^{56}$

The high prevalence of scoliosis (24\%) among ballet dancers with anorexia nervosa might also be attributable to a loss of phosphate caused by dieting and intensive 
Table 1 Sequence of events after institution of total parenteral nutrition (TPN) in two cachectic patients (Weinsier and Krumdieck, $1981^{61}$ )

\begin{tabular}{lll}
\hline & Case 1 & Case 2 \\
\hline Within 48 hours of instituting TPN & Hypophosphataemia & Hypophosphataemia \\
& Hyperglycaemia & Hyperglycaemia \\
& Hetabolic acidosis & Metabolic acidosis \\
& Chest pain & Hypokalaemia \\
& Tachycardia & Lethargy \\
& Hypotension & Tachycardia \\
& Cardiac arrhythmia & Hypotension \\
& Tachypnoea & Apnoea \\
& Adult respiratory distress syndrome & Mechanical ventilation \\
& Mechanical ventilation & Adult respiratory distress syndrome \\
& Episode of gastrointestinal bleeding & Pulmonary infection \\
After correction of hypophosphataemia & Episode of gastrointestinal bleeding \\
& Pulmonary infection & Peritonitis \\
& Sepsis & Sepsis \\
& Persistent cardiopulmonary irregularity & Persistent cardiopulmonary irregularity \\
& Death & Death \\
\hline
\end{tabular}

training. Bergengren published an abstract presenting the hypothesis that anorexia nervosa and scoliosis develop due to phosphate depletion. ${ }^{44}$ Hypophosphataemia and lumbar scoliosis in the spine and uncalcified osteoid were observed in the iliac crest of an anorexia nervosa patient. ${ }^{58}{ }^{59}$ Phosphate depletion might also explain the femoral head collapse in another patient with anorexia nervosa. ${ }^{45}$

Life threatening complications associated with refeeding in anorexia nervosa have been suggested as being caused by hypophosphataemia, with intracellular ATP depletion. ${ }^{60}$ A low serum phosphate level is fatal and may account for sudden cardiac arrest in anorexia nervosa patients. ${ }^{13}$ Weinsier and Krumdieck described schematically the clinical situation in two cases during total parenteral nutrition (table 1). ${ }^{61}$ Electrocardiography measurements revealed QT prolongation. No discussion of the influence of serum phosphate was put forward. In one case report, heart failure had occurred secondary to severe hypophosphataemia despite oral phosphate supplementation. ${ }^{62}$ In another report, a variety of electrocardiographic abnormalities were found in $86 \%$ of patients with anorexia nervosa. ${ }^{63}$ As death is sudden and unexpected in an unknown number of patients, the hypophosphataemia-but more probably phosphate depletion (due to undernutrition) despite normal serum phosphate levels-may be the causative factor. Schocken et al concluded that further clinical studies are needed to define better the full effects of anorexia nervosa and starvation on the heart and to determine the ideal method of nutritional rehabilitation. ${ }^{25}$

Clinically, in anorexia nervosa, hypophosphataemia may be involved in the development of cardiac arrhythmia and explain the small heart size and reversible cardiomyopathy. ${ }^{606465}$ Other symptoms from the heart, such as bradycardia due to atrophy of the myocardium and left ventricular dysarrhythmia, are described in case reports. Reduced stroke output and cardiomyopathy have been described in other patient populations in connection with hypophosphataemia. ${ }^{6}$ Improvement of myocardial function is observed when hypophosphataemia is corrected. ${ }^{66} 67$
Hypophosphataemia has been described in anorexia nervosa patients with neurological complications, acute renal and respiratory failure, congestive heart failure possibly due to a combination of reduced phosphate intake and increased loss via the urine, and precipitated by refeeding. ${ }^{6} 1224-263439606869$ Children with protein energy undernutrition subjected to refeeding may suffer from dysphagia in addition to hypophosphataemia. ${ }^{18}$ In a semistarved male, hypophosphataemia due to alcohol poisoning caused dysphagia. ${ }^{70}$ Within 12 hours of a phosphate infusion, there was marked improvement in his dysphagia and dysarthria. Achalasia, a reduced oesophageal motility due to loss of neurological regulation has been described in anorexia nervosa. ${ }^{60}$ The neurological disturbances caused by hypophosphataemia can be severe, causing delirium, paralysis, and even death. ${ }^{19316061646971}$ In patients with anorexia nervosa, peripheral sensory neuropathy was also present. ${ }^{11}$ The prolonged starvation in some patients may have caused cerebral atrophy. ${ }^{64}$

\section{Treatment/prevention}

Large quantities of nutrients can result in cardiac, pulmonary, haematological, and neuromuscular dysfunction and the amount of phosphate given should be calculated. This condition, described in both anorexia and infant undernutrition, is called the "refeeding syndrome" ${ }^{17}$ Knowledge in the field of refeeding and how to reduce the risk of hypophosphataemia is mostly lacking in the clinical setting. Figure 3 gives a few guidelines, taken from cited references, which could be helpful. Two $\mathrm{mg}$ phosphate/kg body weight over six hours is proposed as a suitable dose in the initial phase and serum phosphate will be restored within 36 hours. ${ }^{72}$ Acute respiratory failure occurs in hypophosphataemic patients with anorexia nervosa. ${ }^{12}$ The patient hypoventilates, in consequence of neuromuscular dysfunction. Rapid improvement after phosphate supplementation for one week, and a stabilised serum phosphate level $(1.2-1.5 \mathrm{mmol} / \mathrm{l})$, indicate the involvement of phosphate depletion. 
1 Berner Y, Shike M. Consequences of phosphate imbalance. Ann Rev Nutr 1988;8:121-48.

2 Stoff J. Phosphate homeostasis and hypophosphatemia. Am f Med 1982;72:489-95.

3 Lentz RD, Brown DM, Kjellstrand CM. Treatment of severe hypophosphatemia. Ann Intern Med 1978;89:941-4.

4 Knochel JP. The pathophysiology and clinical characteristics of severe hypophosphatemia. Arch Intern Med 1977;137: 203-20.

5 Warren SE, Steinberg SM. Acid-base and electrolyte disturbances in anorexia nervosa. Am F Psychiatry 1979;136:415-

6 Wada S, Nagase T, Koike Y, et al. A case of anorexia nervosa Wada S, Nagase T, Koike Y, et al. A case of anorexia nervosa
with acute renal failure induced by rhabdomyolysis; possible with acute renal failure induced by rhabdomyolysis; possible involvement of hypophosphaten

7 Palla B, Litt IF. Medical complications of eating disorders in adolescents. Pediatrics 1988;81:613-23.

8 Zazzo J-F, Troché G, Ruel P, et al. High incidence of hypophosphatemia in surgical intensive care patients: efficacy of phosphorus therapy on myocardial function. Intensive Care Medicine 1995;21:826-31.

9 Håglin L, Burman LÅ, Nilsson M. High prevalence of hypophosphataemia amongst patients with infectious diseases. A retrospective study. F Intern Med 1999;246:45-52.

10 Rock CL, Curran-Celentano J. Nutritional disorder of anorexia nervosa: a review. Int 7 Eat Disord 1994;15:187-203.

11 Cariem AK, Lemmer ER Adams MG, et al. Severe hypophosphataemia in anorexia nervosa. Postgrad Med $\mathcal{F}$ 1994;70:825-7.

12 Gustavsson CG, Eriksson L. Acute respiratory failure in anorexia nervosa with hypophosphataemia. $\mathcal{F}$ Intern Med 1989;225:63-4.

13 Isner J, Roberts W, Heymsfield S, et al. Anorexia nervosa and sudden death. Ann Intern Med 1985;102:49-52.

14 Zipfel S, Löwe B, Reas DL, et al. Long-term prognosis in anorexia nervosa: lessons from a 21-year follow-up study. Lancet 2000;355:721-2.

15 Mezoff AG, Gremse DA, Farrell MK. Hypophosphatemia in the nutritional recovery syndrome. Am $\mathcal{f}$ Dis Child 1989 ; 143:1111-2.

16 Cumming AD, Farquhar JR, Bouchier IAD. Refeeding hypophosphataemia in anorexia nervosa and alcoholism. BMF 1987;295:490-1

17 Bowling TE, Silk DB. Refeeding remembered. Nutrition 1995;11:32-4

18 Worley G, Claerhout S, Combs S. Hypophosphatemia in malnourished children during refeeding. Clin Pediatr (Phila) 1998;37:347-52

19 Oster P, Rieben FW, Schmidt-Gayk H, et al. Lähmungen bei Hypophosphatämie. Dtsch Med Wochenschr 1977;102:14223.

20 Burger GCE, Drummond JC, Sandstead HR, eds. Malnutrition and starvation in Western Netherlands, September 1944 fuly 1945, parts 1 and 2. The Hague: General State Printing Office, 1948.

21 Keys A, Brozek J, Henschel A, et al. The biology of human starvation. Minneapolis, MN: University of Minnesota Press, 1950

22 Schnitker MA, Mattman, Bliss TL. A clinical study of malnutrition in Japanese prisoners of war. Ann Intern Med 1951;35:69-96.

23 Waterlow JC, Golden MHN. Serum inorganic phosphate in protein-energy malnutrition. Eur f Clin Nutr 1994;48:5036.

24 Waldholtz BD, Andersen AE. Hypophosphatemia during starvation in anorexia nervosa. Int f Eat Disord 1988;7:551-

25 Schocken DD, Holloway JD, Powers PS. Weight loss and the heart. Effects of anorexia nervosa and starvation. Arch Intern Med 1989;149:877-81.

26 Comerci GD. Medical complications of anorexia nervosa and bulimia nervosa. Med Clin North Am 1990;74:1293310.

27 Dominguez JH, Gray RW, Lemann J. Dietary phosphate deprivation in women and men: effects on mineral and acid balances, parathyroid hormone and the metabolism of 25-OH-vitamin D. f Clin Endocrinol Metab 1976;43:105668.

28 Schwartz KB, Zimmerman DC, Alpers DH, et al. Gender differences in antacid-induced phosphate deprivation in rats. Gastroenterology 1985;89:313-20.

29 Henry Y, Gueguen L, Rérat A. Influence of the level of dietary phosphorus on the voluntary intake of energy and dietary phosphorus on the voluntary intake of energy and
metabolic utilization of nutrients in the growing rat. $B r f$ Nutr 1979;42:127-37.

30 Emmet M, Seldin DW. Disturbances in acid-base balance during hypophosphatemia and phosphate depletion. $A d v$ Exp Med Biol 1977;103:313-25.

31 Sheridan PH, Collins M. Potentially life-threatening hypophosphatemia in anorexia nervosa. $\mathcal{F}$ Adolesc Health Care 1983;4:44-6.

32 Kreusser W, Vetter H, Mittmann H, et al. Cardiac function and metabolism in phosphorous depleted dogs-effects of hormonal stimulation. Adv Exp Med Biol 1982;151:251-8.

33 Fuller TJ, Nichols WW, Brenner BJ, et al. Effects of phosphorus depletion on left ventricular energy generation. Adv Exp Med Biol 1978;103:395-400

34 Van Dissel JT, Gerritsen HJ, Meinders AE. Severe hypophosphatemia in a patient with anorexia nervosa
during oral feeding. Miner Electrolyte Metab 1992;18:365-9.

35 Rigotti NA. Eating disorders. In: Carlson KJ, St Eisensta SA, eds. Primary care of women. 1995: 443-9.
36 Hertlova M, Lata J, Vodicka J, et al. Anorexia nervosa-the views of the internist. Cas Lek Cesk 1994;133:759-61.

37 Kohaut EC, Klish WJ, Beachler CW, et al. Reduced renal acid excretion in malnutrition: a result of phosphate depletion. Am F Clin Nutr 1977;30:861-7.

38 Krapf R, Vetsch R, Vetsch W, et al. Chronic metabolic acidosis increases the serum concentration of 1,25 dihydroxyvitamin $\mathrm{D}$ in humans by stimulating its production rate. F Clin Invest 1992;90:2456-63.

39 Mira M, Stewart PM, Vizzard J, et al. Biochemical abnormalities in anorexia nervosa and bulimia. Ann Clin Biochem 1987;24:29-35.

40 Cuisinier-Gleizes P, Thomasset M, Sainteny-Debove F, et al. Phosphorus deficiency, parathyroid hormone and bone resorption in the growing rat. Calcif Tissue Res 1976;20:23549.

41 Ivey JL, Morey ER, Baylink DJ. The effects of phosphate depletion on bone. Adv Exp Med Biol 1978;103:373-80.

42 Parfitt A, Villanueva A. Hypophosphatemia and osteoblast function in human bone disease. Adv Exp Med Biol 1982:151:209-16.

43 Corvilain J, Abramow M. Growth and renal control of plasma phosphate. F Clin Endocrinol Metab 1972;34:452-9.

44 Bergengren $\mathrm{H}$. Phosphorus deficiency as a common cause of two related diseases. 6th International workshop on phosphate and other minerals. Abstract. Verona, Italy, 24-26 June 1983.

45 Warren M, Shane E, Lee M, et al. Femoral head collapse associated with anorexia nervosa in a 20 -year-old ballet dancer. Clin Orthop 1990;251:171-6.

46 Klein GL, Simmons DJ. Nutritional rickets: thoughts about pathogenesis. Ann Med 1993;25:379-84.

47 Parsons V, Self $M$. Urinary hydroxyproline excretion in phosphate depleted rachitic rats. Nature 1968;217:551-2.

48 Rowe JC, Wood DH, Rowe DW, et al. Nutritional hypophosphatemic rickets in a premature infant fed breast milk. N Engl f Med 1979;300:293-6.

49 Silverstein D, Barac-Nieto M, Spitzer A. Mechanism of renal phosphate retention during growth. Kidney Int 1996;49:1023-6.

50 Håglin L, Essén-Gustavsson B, Kallner A, et al. Hypophosphatemia induced by dietary aluminum hydroxide supplementation in pigs: effects on growth, blood variables, organ weights and renal morphology. Acta Vet Scand 1988;29:919 .

51 Svensson O, Hjerpe A, Reinholt F, et al. The effect of manganese ingestion, phosphate depletion, and starvation on the morphology of the epiphyseal growth plate. Clin Orthop 1985;197:286-94.

52 Parsons V, Szmukler G, Brown S, et al. Fracturing osteoporosis in young women with anorexia nervosa. Calcif Tissue Int 1983;35:A72.

53 Biller BMK, Saxe V, Herzog DB, et al. Mechanisms of osteoporosis in adult and adolescent women with anorexia nervosa. 7 Clin Endocrinol Metab 1989;68:548.

54 Bachrach LK, Guido D, Katzman D, et al. Decreased bone density in adolescent girls with anorexia nervosa. Pediatrics 1990;86:440-7.

55 Crosby LO, Kaplan FS, Pertschuk MJ, et al. The effect of anorexia nervosa on bone morphometry in young women. Clin Orthop 1985;201:271-7.

56 Bachrach LK, Katzman DK, Litt IF, et al. Recovery from osteopenia in adolescent girls with anorexia nervosa. $\mathcal{F}$ Clin Endocrinol Metab 1991;72:602-6.

57 Sheldon GF, Grzyb S. Phosphate depletion and repletion: relation to parenteral nutrition and oxygen transport. Ann Surg 1975;182:683-9.

58 Kassem M, Eriksen E, Melsen F, et al. Antacid-induced osteomalacia: a case report with a histomorphometric analysis. F Intern Med 1991;229:275-9.

59 Paterson CR, Naismith KJ, Young JA. Severe unexplained hypophosphatemia. Clin Chem 1992;38:104-7.

60 Kohn MR, Golden NH, Shenker IR. Cardiac arrest and delirium: presentations of the refeeding syndrome in severely malnourished adolescents with anorexia nervosa. $\mathcal{F}$ Adolesc Health 1998;22:239-43.

61 Weinsier RL, Krumdieck CL. Death resulting from overzealous total parenteral nutrition: the refeeding syndrome revisited. Am f Clin Nutr 1981;34:393-9.

62 Birmingham CL, Alothman AF, Goldner EM. Anorexia nervosa: refeeding and hypophosphatemia. Int f Eat Disord 1996;20:211-3

63 Alvin P, Zogheib J, Rey C, et al. Severe complications and mortality in mental eating disorders in adolescence. On 99 hospitalized patients. Arch Fr Pediatr 1993;50:755-62.

64 Beaumont PJV, Large M. Hypophosphataemia, delirium and cardiac arrhythmia in anorexia nervosa. Med 7 Aust 1991:155:519-22.

65 Mehler PS. Hypophosphataemia, delirium and cardiac arrhythmia in anorexia nervosa. Med F A ust 1992;157:214.

66 O'Connor LR, Wheeler WS, Bethune JE. Effect of hypophosphatemia on myocardial performance in man. $N$ Engl f Med 1977;297:901-3.

67 Darsee JR, Nutter DO. Reversible severe congestive cardiomyopathy in three cases

68 Backmund H, Mai N, Gerlinghoff M. Lebensbedrohung und Tod bei Anorexia nervosa [Life-threatening complications and death in anorexia nervosa]. Schweiz Arch Neurol Psychiatrie 1990;141:419-28. 
69 Backmund H, Gerlinghoff M. Anorexia nervosa. Bedrohliche neurologische Komplikationen durch Hypophosphatämie [Anorexia nervosa. Severe neurologic complications caused by hypophosphataemia]. Nervenarzt 1986;57 $542-4$.

70 Silvis SE, DiBartolomeo AG, Aaker HM. Hypophosphatemia and neurological changes secondary to oral caloric intake. Am f Gastroenterol 1980;73:215-22.

71 Hall DE, Kahan B, Snitzer J. Delirium associated with hypophosphatemia in a patient with anorexia nervosa. $f$ Adolesc Health 1994;15:176-8.

72 Vannatta JB, Whang R, Papper S. Efficacy of intravenous phosphorus therapy in the severely hypophosphatemic patient. Arch Intern Med 1981;141:885-7.

73 Bufano G, Bellini C, Cervellin G, et al. Enteral nutrition in anorexia nervosa. Fournal of Parenteral and Enteral Nutrition 1990;14:404-7.

74 Silvis SE, Paragas PD. Paresthesias, weakness, seizures, and hypophosphatemia in patients receiving hyperalimentation. hypophosphatemia in patients recei
75 Walker J, Roberts SL, Halmi KA, et al. Caloric requirements of weight gain in anorexia nervosa. Am f Clin Nutr 1989;32: $1396-400$

76 Thompson JS, Hodges RE. Preventing hypophosphatemia during total parenteral nutrition. Fournal of Parenteral and Entreral Nutrition 1984;8:137-9.

77 Mehler PS, Weiner KL. Anorexia nervosa and total parenteral nutrition. Int F Eat Disord 1993;14:297-304.

78 Lloyd CW, Johnson CE Management of hypophosphatemia. Clin Pharm 1988;7:123-8.

79 Bugg NC, Jones JA. Hypophosphataemia. Pathophysiology, effects and management on the intensive care unit. Anaesthesia 1998;53:895-902.

80 Kaysar N, Kronenberg J, Polliack M, et al. Severe hypophosphataemia during binge eating in anorexia nervosa. Arch Dis Child 1991;66:138-9.

81 Kingston M, Al-Siba J MB. Treatment of severe hypophosphatemia: a metabolic consideration in critical care medicine. Crit Care Med 1981;9:772-4.

\section{Medical Anniversary}

Norman Rupert Barrett, 16 May 1903

Norman Rupert Barrett (1903-79) was born in Adelaide, Australia and educated at Eton, Trinity Cambridge, and St Thomas' Hospital where he qualified in 1928. He became consultant thoracic surgeon to St Thomas' and Brompton Chest hospitals and editor of the journal, Thorax. He is remembered now for his clear exposition of metaplasia of the lower oesophagus-Barrett's oesophagitis. - D G fames 